\title{
Two-Dimensional $\mathrm{CdX} / \mathrm{C}_{2} \mathrm{~N}(\mathrm{X}=\mathrm{S}$, Se) Heterostructures as Potential Photocatalysts for Water Splitting: A DFT Study
}

\author{
M. R. Ashwin Kishore, Karin Larsson, and Ponniah Ravindran* \\ Cite This: ACS Omega 2020, 5, 23762-23768 \\ Read Online
}

ABSTRACT: Global environmental issues, in addition to limited fossil fuel resources, are being addressed by quests in search of efficient visible-light-driven water splitting catalysts for hydrogen production. The photocatalytic water splitting activities of $\mathrm{CdX} / \mathrm{C}_{2} \mathrm{~N}(\mathrm{X}=\mathrm{S}, \mathrm{Se})$ heterostructures have been investigated here using hybrid density functional theory calculations. The calculated band gaps of $\mathrm{CdS} / \mathrm{C}_{2} \mathrm{~N}$ and $\mathrm{CdSe} / \mathrm{C}_{2} \mathrm{~N}$ heterostructures are 1.48 and $2.12 \mathrm{eV}$, respectively. These are ideal band gap values that make possible harvesting of more visible light from the solar spectrum, which will result in high solar to energy conversion efficiencies. Charge density difference analysis shows that the charge redistributions mainly occur in the interface regions and that the charges transfer from the $\mathrm{C}_{2} \mathrm{~N}$ to $\mathrm{CdX}$ layers. It is interesting to note that the

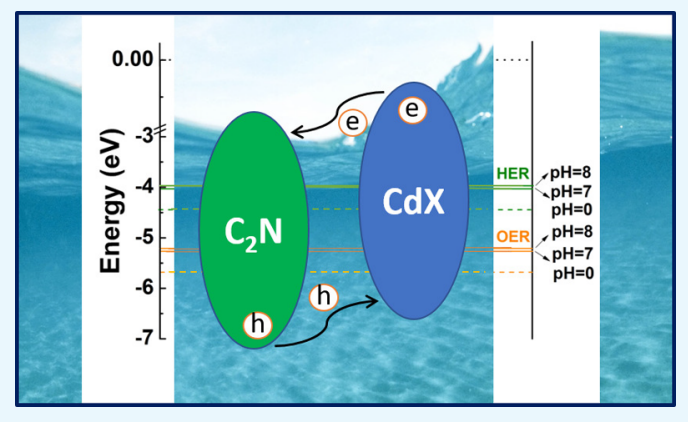
$\mathrm{CdX} / \mathrm{C}_{2} \mathrm{~N}$ heterostructures possess a type-II band alignment, where the relative band alignment of the $\mathrm{C}_{2} \mathrm{~N}$ and $\mathrm{CdX}$ monolayers promotes a spatial separation of the electrons (that resides in $\mathrm{C}_{2} \mathrm{~N}$ ) and holes $($ that resides in $\mathrm{CdX}$ ). Importantly, the band edges of the heterostructures straddle the water redox potential under different $\mathrm{pH}$ conditions. This study demonstrates that the $\mathrm{CdS} / \mathrm{C}_{2} \mathrm{~N}$ and $\mathrm{CdSe} / \mathrm{C}_{2} \mathrm{~N}$ heterostructures are suitable materials to split water (from various sources) in different ranges of $\mathrm{pH}$ values.

\section{INTRODUCTION}

Consumption of fossil fuels and the industrial revolution pose a severe threat to the global environment. Using an alternative energy with low or no greenhouse gas emissions is one of the promising ways to mitigate the energy and environmental issues. The production of hydrogen (being a clean fuel) from water splitting, with the help of sunlight, is a promising way. ${ }^{1-3}$ $\mathrm{TiO}_{2}, \mathrm{ZnO}$, and $\mathrm{SrTiO}_{3}$ are the well-known photocatalysts that exhibit high photocatalytic activities. However, they are not interesting anymore because of their wide band gaps, which limit their absorption of the visible part of the solar spectra. Screening materials with an optimal band gap (1.8 to $2.2 \mathrm{eV}$ ) and a favorable band edge position with respect to the water redox potentials is a key step in photocatalysis. ${ }^{4}$

The utilization of nanostructured materials for energy conversion and storage exhibits improved efficiency. This is due to their large surface areas, low diffusion length, and unique possibilities to tune the rich surface active sites. ${ }^{5-7}$ Nanostructured two-dimensional materials (2D) have gained significant interest owing to their remarkable properties, such as enhanced electron-hole separation, fast mobility of photogenerated charge carriers, and reduced recombination rate. ${ }^{8,9}$ However, in most cases, the pure form would not be efficient enough to show improved efficiencies. Tailoring the materials, with the purpose of achieving the required functionalities and efficiencies, is the primary strategy in materials science research today. Doping, introducing defects, layer-by-layer or heterostructure mapping, chemical adsorp- tion, strain engineering, and external electric field are examples of other widely used approaches, and each one has its own advantage and disadvantage. ${ }^{10-12}$

Among the strategies mentioned above, van der Waals (vdW) stacking of two different 2D materials has been shown to exhibit improved photocatalytic activity, far beyond the activities for the corresponding single components. ${ }^{13,14}$ This is due to the effect of interfacial electron relocalization and the resulting built-in electric field. This specific stacking spatially separates the charge carriers, thereby preventing charge recombination. It also triggers the redox reactions on the different component layers. In addition, the $2 \mathrm{D}$ heterostructure can induce novel active sites for the photocatalytic reactions to occur. To date, several $2 \mathrm{D}$ heterostructures have been proposed as catalysts for photocatalytic water splitting. ${ }^{9,15}$ Despite the experimental and theoretical efforts in developing potential catalysts for hydrogen production, it is still a great challenge to develop a promising photocatalyst with high activity and stability.

Received: June 13, 2020

Accepted: July 24, 2020

Published: September 9, 2020 
Table 1. Calculated Lattice Constant $(a)$ in $\AA$, Interlayer Distance $(D)$ in $\AA$, Buckling Constant $\left(\delta_{z}\right)$ in $\AA$, Which Stems from the Difference between the Smallest and Largest $z$ Coordinates of Atoms, Bonding Distance between Cd and S/Se in $\AA$, Bonding Distance between $\mathrm{C}$ and $\mathrm{C}$ in $\AA$, Bonding Distance between $\mathrm{C}$ and $\mathrm{N}$ in $\AA$, Interface Adhesion Energy $\left(E_{\mathrm{ad}}\right)$ in $\mathrm{eV}$, for the $\mathrm{CdS} / \mathrm{C}_{2} \mathrm{~N}$ and $\mathrm{CdSe} / \mathrm{C}_{2} \mathrm{~N}$ Heterostructures, and Band Gap $\left(E_{\mathrm{g}}\right)$ in eV

\begin{tabular}{ccccccccc} 
system & $a$ & $D$ & $\delta_{z}$ & $d_{\mathrm{Cd}-\mathrm{S} / \mathrm{Se}}$ & $d_{\mathrm{C}-\mathrm{C}}$ & $d_{\mathrm{C}-\mathrm{N}}$ & $E_{\mathrm{ad}}$ & $E_{\mathrm{g}}$ \\
$\mathrm{CdS}$ & 4.23 & & 0.07 & 2.44 & & & & 2.72 \\
$\mathrm{CdSe}$ & 4.40 & & 0.41 & 2.57 & & & & \\
$\mathrm{C}_{2} \mathrm{~N}$ & 8.32 & & & & $1.43 / 1.46$ & 1.33 & 2.53 \\
$\mathrm{CdS} / \mathrm{C}_{2} \mathrm{~N}$ & 8.32 & 2.97 & 0.86 & 2.45 & $1.43 / 1.47$ & 1.34 & -0.66 \\
$\mathrm{CdSe} / \mathrm{C}_{2} \mathrm{~N}$ & 8.40 & 3.25 & 1.02 & 2.52 & $1.43 / 1.48$ & 1.34 & -0.24 & 2.12 \\
\hline
\end{tabular}
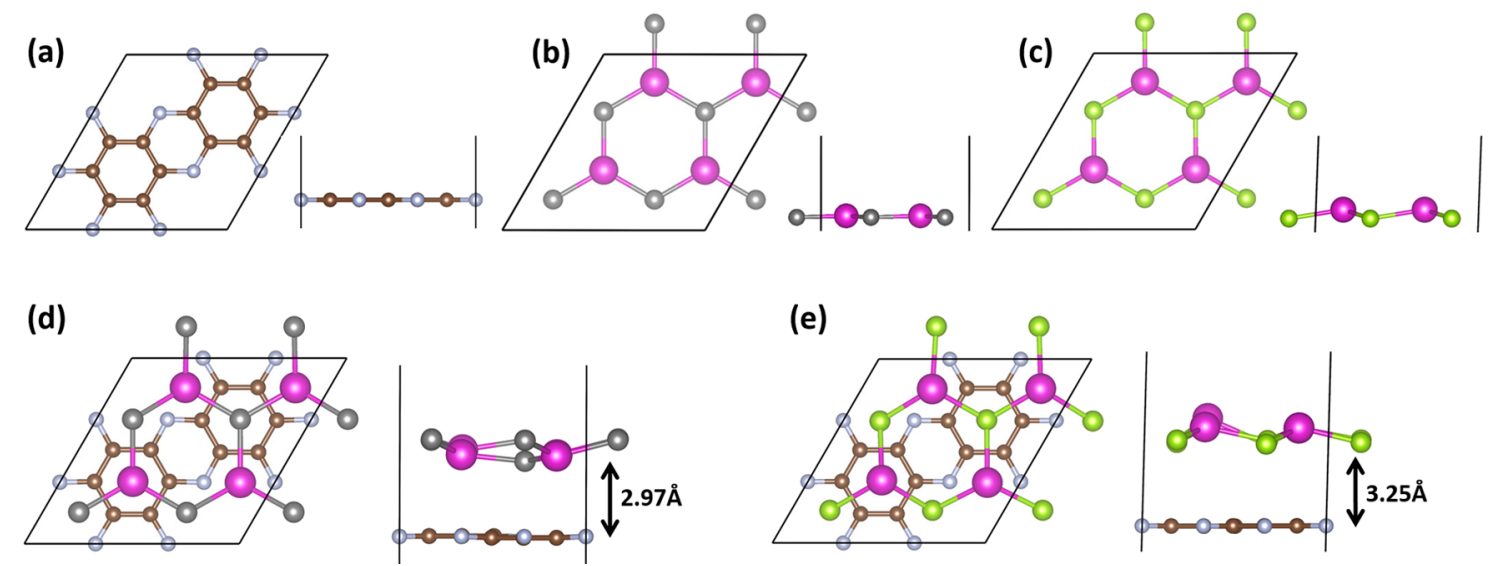

Figure 1. Schematic geometrical structure of (a) $\mathrm{C}_{2} \mathrm{~N}$, (b) CdS, (c) CdSe, (d) the $\mathrm{CdS} / \mathrm{C}_{2} \mathrm{~N}$ heterostructure, and $(e)$ the $\mathrm{CdSe} / \mathrm{C}_{2} \mathrm{~N}$ heterostructure in top and side views. C, N, Cd, S, and Se atoms are marked in brown, lavender, magenta, gray, and green, respectively.

Cadmium sulfide (CdS) is an attractive material that possesses a direct band gap of $2.4 \mathrm{eV}$ (at room temperature), which facilitates more abundant visible light absorption. ${ }^{2}$ Also, its conduction band edge position favors a stronger water reduction power, as compared with well-known photocatalysts such as $\mathrm{TiO}_{2}, \mathrm{ZnO}$, and $\mathrm{SrTiO}_{3} .{ }^{16}$ The shortcomings of the $\mathrm{CdS}$ nanoparticle (small adsorption capacity toward reactants, poor photostability, and increased recombination rate) can be overcome by coupling with other semiconductors. $3,17-19$ Recently, it has been reported that the single layer of CdS, cleaved out from the wurtzite phase, is a potential candidate for visible light photocatalysis. ${ }^{20,21}$ Since then, there has been an explosive growth in the use of CdS monolayers, stacked with other $2 \mathrm{D}$ materials, to explore the photocatalytic properties. $^{22-26}$

In the present study, we propose to stack $\mathrm{CdX}(\mathrm{X}=\mathrm{S}, \mathrm{Se})$ layers with $2 \mathrm{D}-\mathrm{C}_{2} \mathrm{~N}$ since the latter is a well-studied material for various catalysis applications. ${ }^{27-31}$ In addition, the $\mathrm{C}_{2} \mathrm{~N}$ monolayer forms a well-matched interface with the $\mathrm{CdX}$ layer. Detailed hybrid density functional calculations reveal that the $\mathrm{CdS} / \mathrm{C}_{2} \mathrm{~N}$ and $\mathrm{CdSe} / \mathrm{C}_{2} \mathrm{~N}$ heterostructures are promising photocatalysts for overall water splitting. Further, their electronic band gaps and the band edge positions are suitable for visible light photocatalysis. The type-II band alignment and charge transfer mechanism reveal the presence of spatial charge separation upon photoexcitation (which results in reduced carrier recombination rate). All these observations favor the enhanced photocatalytic activities in $\mathrm{CdS} / \mathrm{C}_{2} \mathrm{~N}$ and $\mathrm{CdSe} / \mathrm{C}_{2} \mathrm{~N}$ heterostructures.

\section{RESULTS AND DISCUSSION}

Structural and Electronic Properties. Before discussing the $\mathrm{CdS} / \mathrm{C}_{2} \mathrm{~N}$ and $\mathrm{CdSe} / \mathrm{C}_{2} \mathrm{~N}$ heterostructures, let us take a look at the structural properties of freestanding $\mathrm{CdS}$, CdSe, and $\mathrm{C}_{2} \mathrm{~N}$ layers (see Table.1). The optimized structure of the $\mathrm{C}_{2} \mathrm{~N}$ monolayer is shown in Figure 1a. In the $\mathrm{C}_{2} \mathrm{~N}$ structure, the benzene rings are bridged by pyrazine rings in such a way that periodic holes are present. The calculated in-plane bond lengths $(\mathrm{C}-\mathrm{C}=1.429 / 1.468 \AA ; \mathrm{C}-\mathrm{N}=1.336 \AA)$ are in good agreement with reported values. ${ }^{32,33} 2 \times 2$ supercells of $\mathrm{CdS}$ and CdSe monolayers are illustrated in Figure 1 b,c. CdS and CdSe monolayers were cleaved out from the (0001) plane of the wurtzite phase of $\mathrm{CdS}$ and $\mathrm{CdSe}$, respectively. The geometry-optimized $\mathrm{CdS}$ and $\mathrm{CdSe}$ monolayers ended up with corrugated structures (similar to that of silicene) ${ }^{34}$ with buckling parameters of 0.07 and $0.41 \AA$, respectively. The optimized lattice parameters for CdS $(a=4.23 \AA)$ and CdSe $(a$ $=4.40 \AA)$ are consistent with values obtained from similar calculations. $^{21,35}$ In the present study, in order to construct $\mathrm{CdS} / \mathrm{C}_{2} \mathrm{~N}$ and $\mathrm{CdSe} / \mathrm{C}_{2} \mathrm{~N}$ heterostructures, $2 \times 2 \mathrm{CdS}$ and $\mathrm{CdSe}$ monolayers were stacked on top of a $\mathrm{C}_{2} \mathrm{~N}$ monolayer (as shown in Figure 1d,e). The lattice mismatch between these layers is only $0.57 \%$ for $\mathrm{CdS} / \mathrm{C}_{2} \mathrm{~N}$ and $1.8 \%$ for $\mathrm{CdSe} / \mathrm{C}_{2} \mathrm{~N}$, which is suitable in the construction of these heterostructures. Due to the presence of the $\mathrm{C}_{2} \mathrm{~N}$ monolayer, both $\mathrm{CdS}$ and $\mathrm{CdSe}$ layers were observed to undergo somewhat larger geometric distortions. Thus, the buckling parameters increased to $0.86 \AA$ for the case of $\mathrm{CdS}$ and $1.02 \AA$ for the case of CdSe (as can be seen in Figure 1d,e). Moreover, the calculated equilibrium interlayer distances were $2.97 \AA$ for the $\mathrm{C}_{2} \mathrm{~N}$ and $\mathrm{CdS}$ monolayers and $3.25 \AA$ for the $\mathrm{C}_{2} \mathrm{~N}$ and $\mathrm{CdSe}$ monolayers, which are the values of vdW equilibrium spacings.

To address the thermodynamic stabilities of the $\mathrm{CdX} / \mathrm{C}_{2} \mathrm{~N}$ heterostructures, the interface adhesion energies were calculated according to the following equation 
(a)

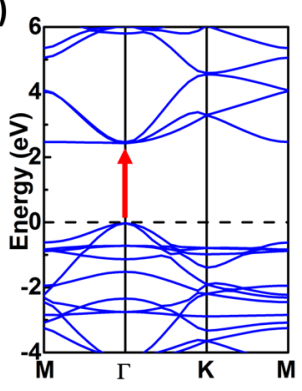

(b)

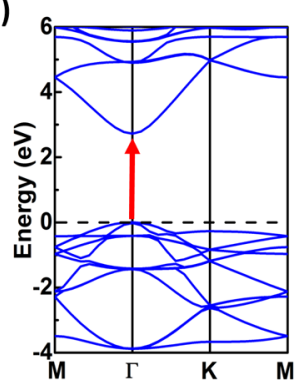

(c)

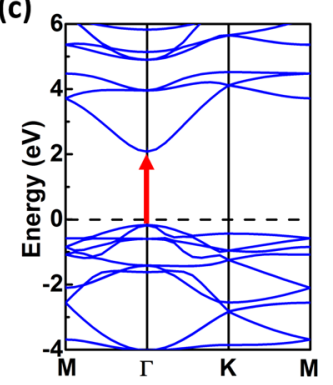

Figure 2. Calculated band structure of the (a) $\mathrm{C}_{2} \mathrm{~N},(\mathrm{~b}) \mathrm{CdS}$, and (c) CdSe monolayers obtained from the HSE06 functional. The Fermi level is set to zero.

$$
E_{\mathrm{ad}}=E_{\mathrm{CdX}-\mathrm{C}_{2} \mathrm{~N}}-E_{\mathrm{CdX}}-E_{\mathrm{C}_{2} \mathrm{~N}}
$$

where $E_{\mathrm{CdX}-\mathrm{C}_{2} \mathrm{~N}}, E_{\mathrm{CdX}}$, and $E_{\mathrm{C}_{2} \mathrm{~N}}$ are the total energies of the relaxed $\mathrm{CdX} / \mathrm{C}_{2} \mathrm{~N}$ heterostructure, $\mathrm{CdX}$, and $\mathrm{C}_{2} \mathrm{~N}$ monolayers, respectively. The calculated interface adhesion energies were -0.66 , and $-0.24 \mathrm{eV}$ for $\mathrm{CdS} / \mathrm{C}_{2} \mathrm{~N}$ and $\mathrm{CdSe} / \mathrm{C}_{2} \mathrm{~N}$, respectively. The negative adhesion energies indicate that the $\mathrm{CdX} / \mathrm{C}_{2} \mathrm{~N}$ heterostructures can form a stable interface.

The calculated electronic band structures of $\mathrm{C}_{2} \mathrm{~N}, \mathrm{CdS}$, and CdSe monolayers using the GGA-PBE functional are displayed in Figure S1 (in the Supplementary Information). As can be seen in Figure S1, it is clear that the $\mathrm{C}_{2} \mathrm{~N}, \mathrm{CdS}$, and CdSe monolayers are direct band gap semiconductors, as their valence band maximum (VBM) and conduction band minimum (CBM) lie at the $\Gamma$ point in the Brillouin zone. The calculated band gap values for the $\mathrm{C}_{2} \mathrm{~N}, \mathrm{CdS}$, and CdSe monolayers are $1.66,1.66$, and $1.31 \mathrm{eV}$, respectively. In order to predict the photocatalytic properties more reliably, the electronic properties need to be accurately calculated. It is wellknown that the PBE functional underestimates the band gap ${ }^{36}$ and in some cases it may misjudge the band dispersion. Therefore, the band structure and density of states (DOS) have here been calculated using the HSE06 functional since it accurately describes the exchange-correlation energy of electrons in solids.

The band structure of $\mathrm{C}_{2} \mathrm{~N}, \mathrm{CdS}$, and $\mathrm{CdSe}$ monolayers, calculated with the HSE06 functional, is shown in Figure 2. The calculated band gap value of $\mathrm{C}_{2} \mathrm{~N}, \mathrm{CdS}$, and $\mathrm{CdSe}$ monolayers are $2.46,2.72$, and $2.53 \mathrm{eV}$, respectively. It is to be noted that the valence band of the $\mathrm{C}_{2} \mathrm{~N}$ monolayer (along $\Gamma-$ $M$ and $\Gamma-K$ ) and the conduction band (along $\Gamma-K$ ) are well dispersed. Hence, the band structure is expected to have a relatively low hole effective mass along the $\Gamma-M$ and $\Gamma-K$ directions as well as a low electron effective mass along the $\Gamma-$ $K$ direction. There are, thus, high hole and electron mobilities in this type-specific system (since the effective mass is inversely proportional to the carrier mobility). Similarly, for the $\mathrm{CdS}$ and $\mathrm{CdSe}$ monolayer cases, the bands in the valence and conduction edges are well dispersed, leading to a low effective mass of charge carriers. These observations lead to the conclusion that the photogenerated electrons and holes would respond quickly, which results in improved carrier mobilities and reduced recombination rates in these heterostructures and thus high photocatalytic efficiency.

Figure $3 \mathrm{a}, \mathrm{d}$ shows the band structures of the $\mathrm{CdS} / \mathrm{C}_{2} \mathrm{~N}$ and $\mathrm{CdSe} / \mathrm{C}_{2} \mathrm{~N}$ heterostructures, as calculated using the HSE06 functional, respectively. Both $\mathrm{CdS} / \mathrm{C}_{2} \mathrm{~N}$ and $\mathrm{CdSe} / \mathrm{C}_{2} \mathrm{~N}$ heterostructures preserve the direct band gap behavior, and the calculated band gaps are 1.48 and $2.12 \mathrm{eV}$, respectively.

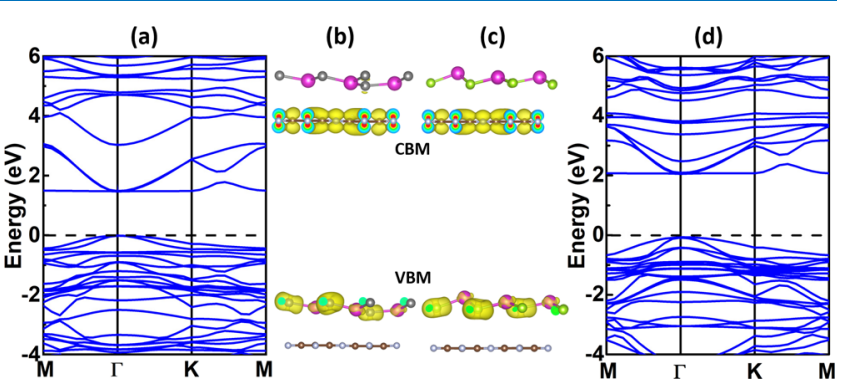

Figure 3. Calculated band structure of (a) $\mathrm{CdS} / \mathrm{C}_{2} \mathrm{~N}$ and (d) $\mathrm{CdSe} /$ $\mathrm{C}_{2} \mathrm{~N}$ heterostructures (obtained from the HSE06 functional). Band decomposed charge densities, corresponding to the VBM and CBM of the (b) $\mathrm{CdS} / \mathrm{C}_{2} \mathrm{~N}$ and (c) $\mathrm{CdSe} / \mathrm{C}_{2} \mathrm{~N}$ heterostructures, are shown with an isosurface value of $0.006 e \AA^{-3}$. The Fermi level is set to zero.

Notably, the ideal band gap for a semiconductor to harvest more visible light from the solar spectrum is $1.5 \mathrm{eV}^{37}$ Interestingly, the calculated band gaps of the $\mathrm{CdS} / \mathrm{C}_{2} \mathrm{~N}$ and $\mathrm{CdSe} / \mathrm{C}_{2} \mathrm{~N}$ heterostructures are 1.48 and $2.12 \mathrm{eV}$. Therefore, it could absorb more abundant visible light, which is about $42 \%$ of the solar spectrum. This result suggests that these materials possess high solar energy conversion efficiency and thus improved photocatalytic water splitting activity.

Figure $3 b, c$ schematically presents the band-decomposed charge density, corresponding to the VBM and CBM at the $\Gamma$ point for the $\mathrm{CdS} / \mathrm{C}_{2} \mathrm{~N}$ and $\mathrm{CdSe} / \mathrm{C}_{2} \mathrm{~N}$ heterostructures, respectively. It is evident from this analysis that the charges at the VBM are from CdX layers, whereas the charges at the CBM are from the $\mathrm{C}_{2} \mathrm{~N}$ monolayer. Hence, upon photoexcitation, the electrons and holes will reside at the $\mathrm{C}_{2} \mathrm{~N}$ and $\mathrm{CdX}$ layers, respectively. This extends the lifetime of charge carriers as the charge carriers are spatially well separated, and this would result in a reduced recombination rate. It is to be noted that the essential criteria for $2 \mathrm{D}$ semiconductors to be used for photocatalytic water splitting applications are direct band gap, high carrier mobility, efficient charge separation, and excellent optical absorptivity. The $\mathrm{CdS} / \mathrm{C}_{2} \mathrm{~N}$ and $\mathrm{CdSe} / \mathrm{C}_{2} \mathrm{~N}$ heterostructures and their respective material layers have here been shown to meet all the above criteria, which indicate that these systems may be promising photocatalysts. However, their water redox capabilities have to be identified in order to confirm its potential for water splitting applications.

In order to determine the character of electrons at the band edges, the total DOSs (TDOS) and orbital projected density of states (PDOSs) have been calculated (with results displayed in Figure 4). As can be seen from the TDOSs, the VBM is dominated by carriers from $\mathrm{CdX}$, whereas the $\mathrm{CBM}$ is dominated by electrons from the $\mathrm{C}_{2} \mathrm{~N}$ monolayer. This result 

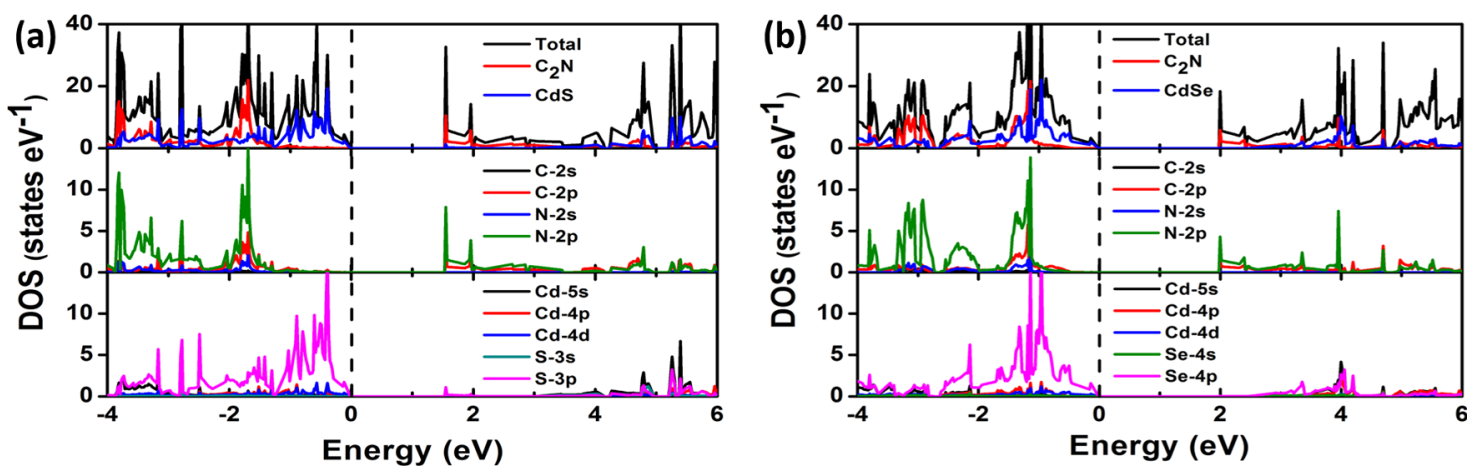

Figure 4. Calculated total and orbital projected DOSs of (a) CdS/ $\mathrm{C}_{2} \mathrm{~N}$ and (b) CdSe/ $\mathrm{C}_{2} \mathrm{~N}$ heterostructures (using the HSE06 functional). The Fermi level is set to zero.

(a)

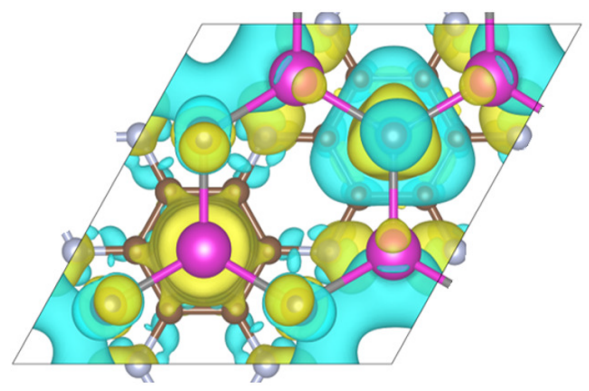

(b)
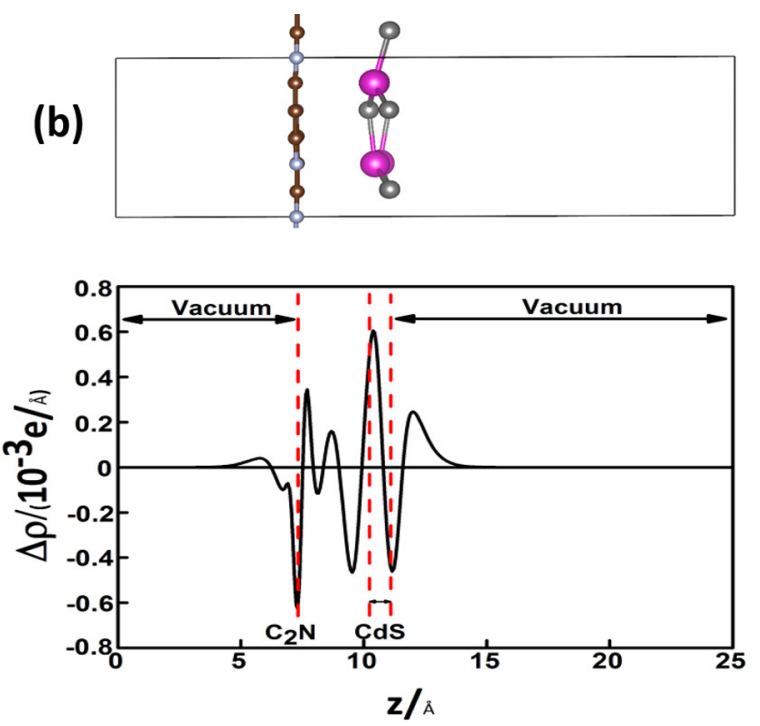

(c)

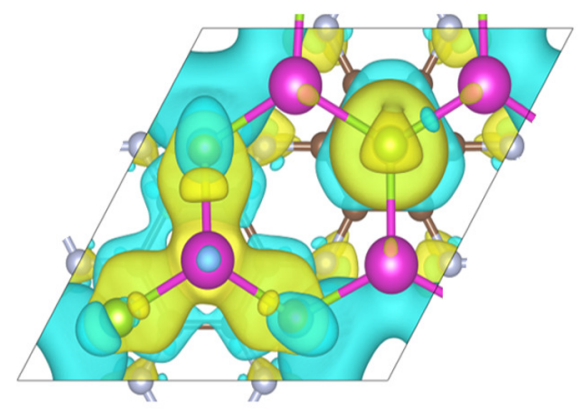

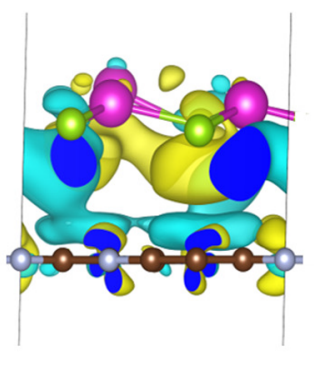

(d)

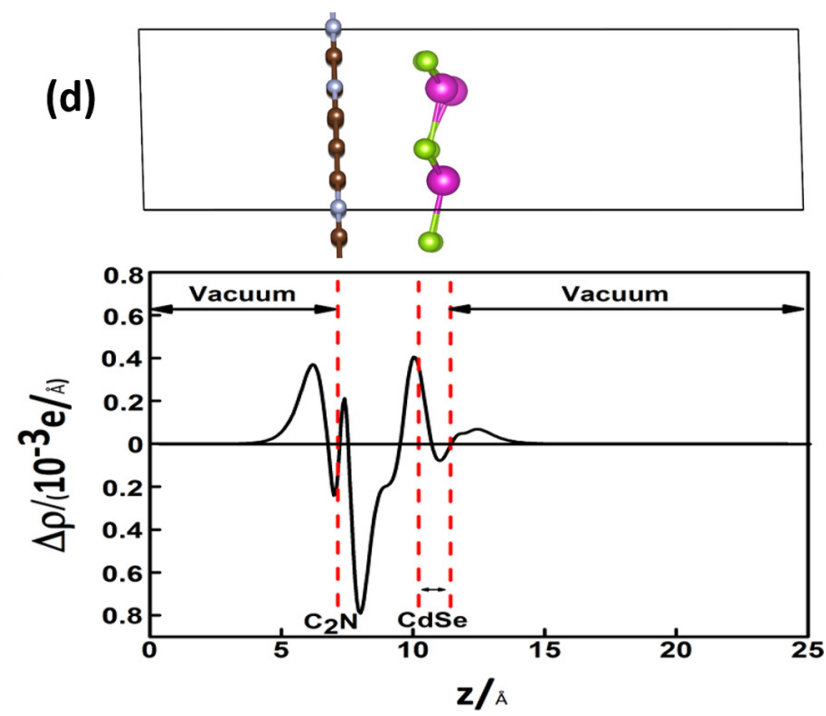

Figure 5. Calculated charge density difference for (a) CdS $/ \mathrm{C}_{2} \mathrm{~N}$ and $(\mathrm{c}) \mathrm{CdSe} / \mathrm{C}_{2} \mathrm{~N}$ heterostructures. Planar averaged charge density difference, $\Delta \rho$ along the $z$ direction for the (b) $\mathrm{CdS} / \mathrm{C}_{2} \mathrm{~N}$ and (d) $\mathrm{CdSe} / \mathrm{C}_{2} \mathrm{~N}$ heterostructures.

suggests that the charge separation will be efficient in these heterostructures. The PDOS of $\mathrm{C}_{2} \mathrm{~N}$ shows that the $2 \mathrm{p}$ orbital of nitrogen is the main contributor to the valence band, with small contributions from the $\mathrm{C} 2 \mathrm{p}$ and $\mathrm{N} 2 \mathrm{~s}$ states, whereas the conduction band originates from the $\mathrm{C} 2 \mathrm{p}$ and $\mathrm{N} 2 \mathrm{p}$ states. In the case of $\mathrm{CdX}$ monolayers, the valence band mainly originates from the $\mathrm{S} 3 \mathrm{p} / \mathrm{Se} 4 \mathrm{p}$ states, with negligible contributions from $\mathrm{Cd} 4 \mathrm{~d}$ and $\mathrm{Cd} 4 \mathrm{p}$ states, whereas the conduction band originates from the hybridization of $S 3 p / S e$ $4 \mathrm{p}$ and $\mathrm{Cd} 5 \mathrm{~s}$ states. Moreover, the VBM of the CdX 
monolayers is positioned at higher energies than that of the $\mathrm{C}_{2} \mathrm{~N}$ monolayer, whereas the CBM of the $\mathrm{C}_{2} \mathrm{~N}$ monolayer is positioned at a lower energy than those of the $\mathrm{CdX}$ monolayers. This observation clearly indicates that the CdS/ $\mathrm{C}_{2} \mathrm{~N}$ and $\mathrm{CdSe} / \mathrm{C}_{2} \mathrm{~N}$ heterostructures are of a typical type-II staggered band alignment, which is the most crucial for photocatalytic water splitting.

Charge Transfer and Separation Mechanism. In order to understand the charge transfer processes during the formation of the $\mathrm{CdX} / \mathrm{C}_{2} \mathrm{~N}$ heterostructures, the charge density differences have been obtained by subtracting the charge densities of pristine $\mathrm{C}_{2} \mathrm{~N}$ and $\mathrm{CdX}$ monolayers from the $\mathrm{CdX} / \mathrm{C}_{2} \mathrm{~N}$ heterostructure (results are displayed in Figure 5) Here, the cyan color indicates the charge depletion, and the yellow color indicates the charge accumulation. As can be seen in Figure 5, the charge redistribution mainly occurs in the interface region. However, there is no charge redistribution observed in the CdX layer further away from the interface region. This is due to the weak van der Waals interaction between the $\mathrm{CdX}$ and $\mathrm{C}_{2} \mathrm{~N}$ layers. To understand the charge transfer processes during the formation of the heterostructures more in detail, the planar charge density difference along the $z$ direction has also been calculated. The positive values denote charge accumulation, and the negative values denote charge depletion. The electron transfer from the $\mathrm{C}_{2} \mathrm{~N}$ side to the $\mathrm{CdX}$ side, i.e., across the interface, is demonstrated in Figure 5. The charge carriers are here shown to be transferred from $\mathrm{C}_{2} \mathrm{~N}$ to $\mathrm{CdX}$, which once again proves that the system is of a type-II conventional heterojunction. Hence, the existence of a type-II band alignment together with the charge transfer between the $\mathrm{CdX}$ and $\mathrm{C}_{2} \mathrm{~N}$ layers results in a considerable interfacial builtin potential. This will favor the electron-hole separation in the heterostructures.

Optical Absorption. The photocatalyst will activate upon photon absorption, so the optical absorption property of a material is crucial in the photocatalytic water splitting mechanism. In order to improve the catalytic efficiency, the photocatalyst should absorb visible light, which is about $42 \%$ of the solar spectra. Figure 6 shows the calculated optical

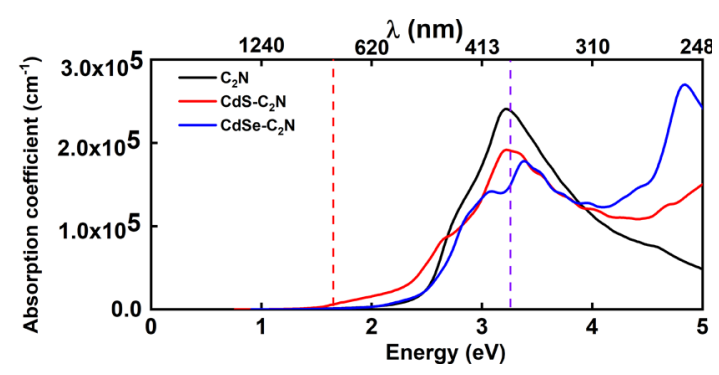

Figure 6. Optical absorption spectrum for the $\mathrm{C}_{2} \mathrm{~N}$ monolayer as well as for the $\mathrm{CdS} / \mathrm{C}_{2} \mathrm{~N}$ and $\mathrm{CdSe} / \mathrm{C}_{2} \mathrm{~N}$ heterostructures (calculated using the PBE functional followed by a rigid energy shift to take the band gap underestimation of the PBE functional into account). The area between the red and the violet dashed lines represents the visible range.

absorption spectra of the $\mathrm{C}_{2} \mathrm{~N}$ monolayer and of the CdS $/ \mathrm{C}_{2} \mathrm{~N}$ and $\mathrm{CdSe} / \mathrm{C}_{2} \mathrm{~N}$ heterostructure, as a function of photon energy versus wavelength. As can be seen in Figure 6, the optical absorption of the $\mathrm{C}_{2} \mathrm{~N}$ monolayer was found to increase with photon energy in the visible light region, while it showed a maximum optical absorption at $3.2 \mathrm{eV}$. The observation presented above has been studied in an earlier work by the present authors. ${ }^{33}$ It was then shown that the absorption peak at $3.2 \mathrm{eV}$ is ascribed to the $n \rightarrow \pi^{*}$ electron transition, involving electron lone pairs of the nitrogen atoms. Although both $\mathrm{CdS} / \mathrm{C}_{2} \mathrm{~N}$ and $\mathrm{CdSe} / \mathrm{C}_{2} \mathrm{~N}$ heterostructures possess an absorption peak in the visible region, the $\mathrm{CdS} / \mathrm{C}_{2} \mathrm{~N}$ heterostructure has an absorption edge that extends a bit to the visible region (as evident in Figure 6). The band gap reduction is attributed to the observed notable red-shift of the absorption edge in the $\mathrm{CdS} / \mathrm{C}_{2} \mathrm{~N}$ heterostructure. Hence, it is evident that $\mathrm{CdS} / \mathrm{C}_{2} \mathrm{~N}$ and $\mathrm{CdSe} / \mathrm{C}_{2} \mathrm{~N}$ heterostructures could harvest the maximum portion (visible light) of the solar spectrum, which helps to improve the efficiency of photocatalytic water splitting.

Hydrogen Production Capabilities. An essential criterion for a material to be employed for water splitting is that the band edge positions should straddle the water redox potentials; i.e., the energy level of the CBM has to lie above the reduction reaction potential $(-4.44 \mathrm{eV}$ vs the vacuum level) and the energy level of the VBM has to lie below the oxidation reaction potential $(-5.67 \mathrm{eV}$ vs the vacuum level). Moreover, the redox potential depends on the $\mathrm{pH}$ value. ${ }^{38,39}$ Hence, the standard redox potentials (with respect to the vacuum level) for $\mathrm{H}^{+} / \mathrm{H}_{2}$ and $\mathrm{O}_{2} / \mathrm{H}_{2} \mathrm{O}$ are calculated using the following equations

$$
\begin{aligned}
& E_{\mathrm{H}^{+} / \mathrm{H}_{2}}^{\mathrm{red}}=-4.44 \mathrm{eV}+\mathrm{pH} \times 0.059 \mathrm{eV} \\
& E_{\mathrm{O}_{2} / \mathrm{H}_{2} \mathrm{O}}^{\mathrm{ox}}=-5.67 \mathrm{eV}+\mathrm{pH} \times 0.059 \mathrm{eV}
\end{aligned}
$$

The band edge positions of $\mathrm{C}_{2} \mathrm{~N}$ and $\mathrm{CdX}$ monolayers before contact (with respect to the vacuum potential) and the hydrogen evolution reaction (HER) and oxygen evolution reaction (OER) potentials at $\mathrm{pH}=0, \mathrm{pH}=7$, and $\mathrm{pH}=8$ are shown in Figure 7. In order to use the photocatalysts for largescale applications, they should be able to split seawater (with its $\mathrm{pH}$ value being $\sim 8$ ). As can be seen in Figure 7, the band edge positions straddle the water redox potentials. This indicates that the studied materials here could not only reduce and oxidize water at $\mathrm{pH}=0$ and 7 but also split the seawater to produce hydrogen. As can also be seen in Figure 4, the CdX/ $\mathrm{C}_{2} \mathrm{~N}$ heterostructures preserve the type-II band alignment after contact. When the $\mathrm{CdX} / \mathrm{C}_{2} \mathrm{~N}$ heterostructures absorb photon energies, electrons in the valence band get promoted to the conduction bands (CBs). Simultaneously, photogenerated holes are created in the valence bands (VBs). These photogenerated electrons in the $\mathrm{CBs}$ of the $\mathrm{CdX}$ layers can easily be moved to the $\mathrm{CB}$ of $\mathrm{C}_{2} \mathrm{~N}$. Conversely, the photogenerated holes in the $\mathrm{VB}$ of $\mathrm{C}_{2} \mathrm{~N}$ can easily be moved to the VB of the CdX due to the type-II band alignment with a small band offset. As a result, the reduction reaction occurs at $\mathrm{C}_{2} \mathrm{~N}$, and the oxidation reaction occurs at the CdX layers. This results in an excellent charge separation and leads to the low carrier recombination rate in the proposed $\mathrm{CdS} / \mathrm{C}_{2} \mathrm{~N}$ and $\mathrm{CdSe} / \mathrm{C}_{2} \mathrm{~N}$ heterostructures. Thus, it improves the photocatalytic hydrogen production.

\section{CONCLUSIONS}

Photocatalytic water splitting activities of $\mathrm{CdS} / \mathrm{C}_{2} \mathrm{~N}$ and $\mathrm{CdSe} / \mathrm{C}_{2} \mathrm{~N}$ heterostructures have in the present study been theoretically demonstrated using accurate density functional calculations. HSE06 band structure analysis reveals that $\mathrm{CdS}$, $\mathrm{CdSe}, \mathrm{C}_{2} \mathrm{~N}, \mathrm{CdS} / \mathrm{C}_{2} \mathrm{~N}$, and $\mathrm{CdSe} / \mathrm{C}_{2} \mathrm{~N}$ heterostructures are direct band gap semiconductors, with band gaps of 2.72, 2.52, 

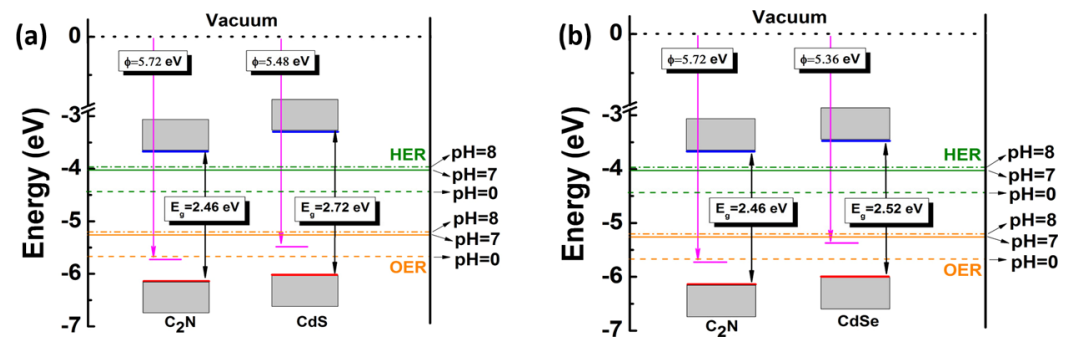

Figure 7. Calculated band edge positions of $(a) \mathrm{C}_{2} \mathrm{~N}$ and $\mathrm{CdS}$ monolayers and (b) $\mathrm{C}_{2} \mathrm{~N}$ and CdSe monolayers (with respect to the vacuum potential). The dashed, solid, and dashed dotted lines are showing water redox potentials at $\mathrm{pH}=0, \mathrm{pH}=7$, and $\mathrm{pH}=8$, respectively.

$2.46,1.48$, and $2.12 \mathrm{eV}$, respectively. The nature of the direct band gaps and the optimum band gap values indicate that the $\mathrm{CdX} / \mathrm{C}_{2} \mathrm{~N}$ heterostructures harvest the visible part of the solar spectrum efficiently. Moreover, the optical absorption spectra confirm that the $\mathrm{CdX} / \mathrm{C}_{2} \mathrm{~N}$ heterostructures could absorb visible light from the solar spectra. DOS analysis of the CdX/ $\mathrm{C}_{2} \mathrm{~N}$ heterostructures shows that the VBMs and CBMs are mainly dominated by the carriers from $\mathrm{CdX}$ and $\mathrm{C}_{2} \mathrm{~N}$ layers, respectively. Therefore, charge carriers are spatially well separated, resulting in a low carrier recombination rate, and the redox reactions occur in two different semiconductors. The band alignment, with respect to the water redox potentials, shows that constructed heterostructures are of a type-II band alignment. Interestingly, the band edges will straddle the redox potentials not only at $\mathrm{pH}=0$ and $\mathrm{pH}=7$ but also at $\mathrm{pH}=8$. Therefore, the $\mathrm{CdX} / \mathrm{C}_{2}$ heterostructure can even split seawater to produce hydrogen. The present results suggest that both the $\mathrm{CdS} / \mathrm{C}_{2} \mathrm{~N}$ and the $\mathrm{CdSe} / \mathrm{C}_{2} \mathrm{~N}$ heterostructures are potential candidates for visible-light photocatalysis for hydrogen production.

\section{COMPUTATIONAL METHODS}

The Vienna ab initio simulation package $(\text { VASP })^{40}$ was used to perform the first-principles calculation. The electron-ion interaction was described using the projector augmented wave (PAW) method. Structure relaxations were carried out using the generalized gradient approximation, as proposed by Perdew, Burke, and Ernzerhof (GGA-PBE), ${ }^{41}$ with van der Waals (vdW) corrections (proposed by Grimme (DFTD2)). ${ }^{42}$ Moreover, the Heyd-Scuseria-Ernzerhof (HSE06) hybrid functional ${ }^{43}$ was used to avoid the disadvantages with DFT-PBE calculations in predicting an accurate band gap. The Brillouin zone was sampled using the Monkhorst-Pack scheme, $^{44}$ and a $k$ mesh of $9 \times 9 \times 1$ and $11 \times 11 \times 1$ was employed for the monolayers of $\mathrm{C}_{2} \mathrm{~N}$ and $\mathrm{CdX}$, respectively. The $5 \times 5 \times 1 k$ mesh was used for the more expensive HSE06 calculations. Furthermore, an energy cutoff, for the plane-wave basis set, was fixed at $520 \mathrm{eV}$. Also, a large vacuum layer of $\sim 20$ A was used to avoid interlayer interactions between periodically repeated model slabs. The convergence criterion for energies was set to $10^{-5} \mathrm{eV}$ between two consecutive SCF cycles, and the forces became converged when the HellmannFeynman forces that were acting on each atom were less than $0.01 \mathrm{eV} / \AA ̊$ upon ionic relaxation. The calculation details for band alignment and optical absorption can be found in ref 33 . The postprocessing of VASP-calculated data has been done using the VASPKIT code. ${ }^{45}$

\section{ASSOCIATED CONTENT}

\section{Supporting Information}

The Supporting Information is available free of charge at https://pubs.acs.org/doi/10.1021/acsomega.0c02804.

Band structure of $\mathrm{C}_{2} \mathrm{~N}, \mathrm{CdS}$, and $\mathrm{CdSe}$ monolayers obtained from the GGA-PBE functional (PDF)

\section{AUTHOR INFORMATION}

\section{Corresponding Author}

Ponniah Ravindran - Department of Physics and Simulation Center for Atomic and Nanoscale MATerials, Central University of Tamil Nadu, Thiruvarur, Tamil Nadu 610101, India; o orcid.org/0000-0003-4611-011X; Email: raviphy@ cutn.ac.in

\section{Authors}

M. R. Ashwin Kishore - Department of Chemistry, Ångström Laboratory, Uppsala University, Uppsala 538751 21, Sweden; (1) orcid.org/0000-0003-0541-3771

Karin Larsson - Department of Chemistry, Angström Laboratory, Uppsala University, Uppsala 538751 21, Sweden

Complete contact information is available at:

https://pubs.acs.org/10.1021/acsomega.0c02804

\section{Notes}

The authors declare no competing financial interest.

\section{ACKNOWLEDGMENTS}

We wish to acknowledge the support from SCANMAT Centre, Central University of Tamil Nadu, India, and SNIC-National Supercomputer Centre, Sweden, for computing time. This research was supported by Department of Science and Technology, India, via grant no. SR/NM/NS-1123/2013.

\section{REFERENCES}

(1) Chen, X.; Shen, S.; Guo, L.; Mao, S. S. Semiconductor-Based Photocatalytic Hydrogen Generation. Chem. Rev. 2010, 110, 65036570.

(2) Kudo, A.; Miseki, Y. Heterogeneous Photocatalyst Materials for Water Splitting. Chem. Soc. Rev. 2009, 38, 253-278.

(3) Xiang, Q.; Yu, J.; Jaroniec, M. Graphene-Based Semiconductor Photocatalysts. Chem. Soc. Rev. 2012, 41, 782-796.

(4) Le Bahers, T.; Rérat, M.; Sautet, P. Semiconductors Used in Photovoltaic and Photocatalytic Devices: Assessing Fundamental Properties from DFT. J. Phys. Chem. C 2014, 118, 5997-6008.

(5) Xu, C.; Anusuyadevi, P. R.; Aymonier, C.; Luque, R.; Marre, S. Nanostructured materials for photocatalysis. Chem. Soc. Rev. 2019, 48, $3868-3902$

(6) Aricò, A. S.; Bruce, P.; Scrosati, B.; Tarascon, J.-M.; Van Schalkwijk, W. Nanostructured Materials for Advanced Energy 
Conversion and Storage Devices. Mater. Sustainable Energy 2010, $148-159$.

(7) Zhu, J.; Zäch, M. Nanostructured materials for photocatalytic hydrogen production. Curr. Opin. Colloid Interface Sci. 2009, 14, 260269.

(8) Khan, K.; Tareen, A. K.; Aslam, M.; Zhang, Y.; Wang, R.; Ouyang, Z.; Gou, Z.; Zhang, H. Recent advances in two-dimensional materials and their nanocomposites in sustainable energy conversion applications. Nanoscale 2019, 11, 21622-21678.

(9) Li, Y.; Li, Y.-L.; Sa, B.; Ahuja, R. Review of two-dimensional materials for photocatalytic water splitting from a theoretical perspective. Catal. Sci. Technol. 2017, 7, 545-559.

(10) Bafekry, A.; Stampfl, C.; Ghergherehchi, M.; Shayesteh, S. F. A first-principles study of the effects of atom impurities, defects, strain, electric field and layer thickness on the electronic and magnetic properties of the $\mathrm{C} 2 \mathrm{~N}$ nanosheet. Carbon 2020, 157, 371-384.

(11) Bafekry, A.; Stampfl, C.; Ghergherehchi, M. Strain, electric-field and functionalization induced widely tunable electronic properties in $\mathrm{MoS}_{2} / \mathrm{BC}_{3}, / \mathrm{C}_{3} \mathrm{~N}$ and $/ \mathrm{C}_{3} \mathrm{~N}_{4}$ van der Waals heterostructures. Nanotechnology 2020, 31, 295202.

(12) Bafekry, A. Graphene-like BC6N single-layer: Tunable electronic and magnetic properties via thickness, gating, topological defects, and adatom/molecule. Phys. E 2020, 118, 113850.

(13) Su, J.; Li, G.-D.; Li, X.-H.; Chen, J.-S. 2D/2D heterojunctions for catalysis. Adv. Sci. 2019, 6, 1801702.

(14) Shang, B.; Jiao, L.; Bao, Q.; Li, C.; Cui, X. Strong interactions in molybdenum disulfide heterostructures boosting the catalytic performance of water splitting: A short review. Nano Mater. Sci. 2019, $1,231-245$

(15) Faraji, M.; Yousefi, M.; Yousefzadeh, S.; Zirak, M.; Naseri, N.; Jeon, T. H.; Choi, W.; Moshfegh, A. Z. Two-dimensional materials in semiconductor photoelectrocatalytic systems for water splitting. Energy Environ. Sci. 2019, 12, 59-95.

(16) Xu, Y.; Schoonen, M. A. A. The absolute energy positions of conduction and valence bands of selected semiconducting minerals. Am. Mineral. 2000, 85, 543-556.

(17) Xiang, Q.; Yu, J. Graphene-based photocatalysts for hydrogen generation. J. Phys. Chem. Lett. 2013, 4, 753-759.

(18) Kamat, P. V. Graphene-based nanoassemblies for energy conversion. J. Phys. Chem. Lett. 2011, 2, 242-251.

(19) Xie, G.; Zhang, K.; Guo, B.; Liu, Q.; Fang, L.; Gong, J. R. Graphene-based materials for hydrogen generation from light-driven water splitting. Adv. Mater. 2013, 25, 3820-3839.

(20) Garg, P.; Kumar, S.; Choudhuri, I.; Mahata, A.; Pathak, B. Hexagonal planar CdS monolayer sheet for visible light photocatalysis. J. Phys. Chem. C 2016, 120, 7052-7060.

(21) Wang, J.; Meng, J.; Li, Q.; Yang, J. Single-layer cadmium chalcogenides: promising visible-light driven photocatalysts for water splitting. Phys. Chem. Chem. Phys. 2016, 18, 17029-17036.

(22) Fan, Y.; Yang, B.; Song, X.; Shao, X.; Zhao, M. Direct Z-scheme photocatalytic overall water splitting on $2 \mathrm{D} \mathrm{CdS} / \mathrm{InSe}$ heterostructures. J. Phys. D: Appl. Phys. 2018, 51, 395501.

(23) Wang, G.; Long, X.; Qi, K.; Dang, S.; Zhong, M.; Xiao, S.; Zhou, T. Two-dimensional CdS/g-C6N6 heterostructure used for visible light photocatalysis. Appl. Surf. Sci. 2019, 471, 162-167.

(24) Luo, X.; Wang, G.; Huang, Y.; Wang, B.; Yuan, H.; Chen, H. A two-dimensional layered $\mathrm{CdS} / \mathrm{C}_{2} \mathrm{~N}$ heterostructure for visible-lightdriven photocatalysis. Phys. Chem. Chem. Phys. 2017, 19, 2821628224.

(25) Li, J.; Wei, W.; Mu, C.; Huang, B.; Dai, Y. Electronic properties of g- $\mathrm{C}_{3} \mathrm{~N}_{4} / \mathrm{CdS}$ heterojunction from the first-principles. Phys. E 2018, 103, 459-463.

(26) Wang, G.; Zhi, Y.; Bo, M.; Xiao, S.; Li, Y.; Zhao, W.; Li, Y.; Li, Y.; He, Z. 2D Hexagonal Boron Nitride/Cadmium Sulfide Heterostructure as a Promising Water-Splitting Photocatalyst. Phys. Status Solidi B 2019, 257, 1900431.

(27) Kishore, M. R. A.; Sjåstad, A. O.; Ravindran, P. Influence of hydrogen and halogen adsorption on the photocatalytic water splitting activity of C2N monolayer: A first-principles study. Carbon 2019, 141, $50-58$.

(28) Li, X.; Zhong, W.; Cui, P.; Li, J.; Jiang, J. Design of Efficient Catalysts with Double Transition Metal Atoms on C2N Layer. J. Phys. Chem. Lett. 2016, 7, 1750-1755.

(29) Mahmood, J.; Jung, S.-M.; Kim, S.-J.; Park, J.; Yoo, J.-W.; Baek, J.-B. Cobalt Oxide Encapsulated in $\mathrm{C}_{2} \mathrm{~N}-\mathrm{h}_{2} \mathrm{D}$ Network Polymer as a Catalyst for Hydrogen Evolution. Chem. Mater. 2015, 27, 4860-4864.

(30) He, B. L.; Shen, J. S.; Tian, Z. X. Iron-Embedded $\mathrm{C}_{2} \mathrm{~N}$ Monolayer: A Promising Low-Cost and High-Activity Single-Atom Catalyst for CO Oxidation. Phys. Chem. Chem. Phys. 2016, 18, 24261-24269.

(31) Zhao, J.; Zhao, J.; Li, F.; Chen, Z. Copper dimer supported on a $\mathrm{C}_{2} \mathrm{~N}$ layer as an efficient electrocatalyst for $\mathrm{CO}_{2}$ reduction reaction: a computational study. J. Phys. Chem. C 2018, 122, 19712-19721.

(32) Kishore, M. R. A.; Ravindran, P. Enhanced Photocatalytic Water Splitting in a $\mathrm{C}_{2} \mathrm{~N}$ Monolayer by $\mathrm{C}$-site Isoelectronic Substitution. ChemPhysChem 2017, 18, 1526-1532.

(33) Kishore, M. R. A.; Ravindran, P. Tailoring the electronic band gap and band edge positions in the $\mathrm{C}_{2} \mathrm{~N}$ Monolayer by $\mathrm{P}$ and $\mathrm{As}$ substitution for photocatalytic water splitting. J. Phys. Chem. C 2017, 121, 22216-22224.

(34) Jose, D.; Datta, A. Structures and chemical properties of silicene: unlike graphene. Acc. Chem. Res. 2014, 47, 593-602.

(35) Zhang, R.; Li, B.; Yang, J. Effects of Stacking Order, Layer Number and External Electric Field on Electronic Structures of FewLayer $\mathrm{C}_{2} \mathrm{~N}-\mathrm{H} 2 \mathrm{D}$. Nanoscale 2015, 7, 14062-14070.

(36) Perdew, J. P. Density Functional Theory and the Band Gap Problem. Int. J. Quantum Chem. 1985, 28, 497-523.

(37) Chowdhury, C.; Karmakar, S.; Datta, A. Monolayer group IVVI monochalcogenides: low-dimensional materials for photocatalytic water splitting. J. Phys. Chem. C 2017, 121, 7615-7624.

(38) Chakrapani, V.; Angus, J. C.; Anderson, A. B.; Wolter, S. D.; Stoner, B. R.; Sumanasekera, G. U. Charge Transfer Equilibria Between Diamond and an Aqueous Oxygen Electrochemical Redox Couple. Science 2007, 318, 1424-1430.

(39) Zhang, X.; Zhao, X.; Wu, D.; Jing, Y.; Zhou, Z. $\mathrm{MnPSe}_{3}$ Monolayer: A Promising 2D Visible-Light Photohydrolytic Catalyst with High Carrier Mobility. Adv. Sci. 2016, 3, 1600062.

(40) Kresse, G.; Furthmüller, J. Efficiency of Ab-Initio Total Energy Calculations for Metals and Semiconductors Using a Plane-Wave Basis Set. Comput. Mater. Sci. 1996, 6, 15-50.

(41) Perdew, J. P.; Burke, K.; Ernzerhof, M. Generalized Gradient Approximation Made Simple. Phys. Rev. Lett. 1996, 77, 3865-3868.

(42) Grimme, S. Semiempirical GGA-Type Density Functional Constructed with a LongRange Dispersion Correction. J. Comput. Chem. 2006, 27, 1787-1799.

(43) Heyd, J.; Scuseria, G. E.; Ernzerhof, M. Hybrid Functionals Based on a Screened Coulomb Potential. J. Chem. Phys. 2003, 118, 8207-8215.

(44) Monkhorst, H. J.; Pack, J. D. Special Points for Brillouin-Zone Integrations. Phys. Rev. B 1976, 13, 5188.

(45) Wang, V. VASPKIT, a Post-Processing Program for the VASP Code; https://vaspkit.sourceforge.net . 2013. 